Ryner Jose C. Carrillo, MD,

Mariano B. Caparas, MD

Department of Otorhinolaryngology

Philippine General Hospital

University of the Philippines Manila
Correspondence: Ryner Jose C. Carrillo, MD Department of Anatomy, College of Medicine University of the Philippines Manila

Pedro Gil St. Ermita, Manila 1000

Phone: (632) 5264194

sENTro Head and Neck Medicine and Surgery 414 West East Center 1336 Taft Ave., Ermita, Manila Phone: (632) 5244455

E-mail:ryner_c@yahoo.com

Reprints will not be available from the author.

No funding support was received for this study. The authors signed a disclosure that they have no proprietary or financial interest with any organization that may have a direct interest in the subject matter of this manuscript, or in any product used or cited in this article.

Presented at the Surgical Innovation Contest (2nd Place), Philippine Society of Otolaryngology Head and Neck Surgery 49th Annual Convention, Westin Philippine Plaza Hotel, Manila, December $1,2005$.

\section{Temporalis Muscle-Coronoid Swing and Forehead Skin Island Flap Reconstruction of the Orbit after Maxillectomy}

\begin{abstract}
The use of local regional flaps is often the most practical and easy means of reconstruction in the management of head and neck tumors. The temporalis muscle coronoid swing has been used to reconstruct the orbital floor and is described in literature as early as 1983. Difficulty is encountered when the medial wall and orbital floor are completely removed and a temporalis muscle-coronoid swing is rendered insufficient for orbital reconstruction.
\end{abstract}

Objective: To describe a combination of forehead island flap and temporalis muscle-coronoid swing in orbital reconstruction.

Design: Surgical Innovation/ Case Report.

Subject: 12-year-old female with recurrent maxillary chondroblastic osteosarcoma one year after chemotherapy.

Methods: The course of tumor excision and defect reconstruction is described.

Results: There was no diplopia or other morbidity. There was minimal added operative time for reconstruction with acceptable results.

Conclusion: Local flaps can be combined in order to repair the orbital floor. Acceptable function with minimal cosmetic deformity can be achieved with less extensive surgery.

Keywords: Forehead flap, temporalis muscle, coronoid, orbit, reconstructive surgical procedures, maxillectomy

LOCAL regional flaps are often the most practical and easy means of reconstruction in the management of head and neck tumors. Not only are the materials for reconstruction near the surgical field, they also require less operative time and skill to accomplish.

Advantageous to the design of local flaps are flexibility and viability. Flexibility requires that restructuring can be done in order to fulfill the need to restore function or cover the defect. Viability is dependent on the blood supply. 


\section{SURGICAL INNOVATIONS}

The temporalis muscle-coronoid swing for orbital floor reconstruction described as early as 1983 by Curioni, et al. ${ }^{1}$ has been used in our institution for the past ten years. Its accompanying advantages and disadvantages were discussed by Pryor et al in 2004².

Recipient site options for the coronoid-temporalis muscle pedicled flap include lamina papyracea, nasal bone, the nasal septum or medial orbital wall. When the medial wall and orbital floor are completely removed, a temporalis muscle-coronoid swing is insufficient for lack of a receiving site.

To overcome this problem, we describe a combination forehead island flap and temporalis muscle-coronoid swing in orbital floor reconstruction.

\section{DESCRIPTION AND DISCUSSION}

A 12-year-old female with an enlarging naso-maxillary chondroblastic osteosarcoma over one year period, underwent a single cycle of chemotherapy and was lost to follow up.

A year after, she returned with an enlarged facial mass involving bilateral maxillary sinuses, pterygoid plates, nasal cavities, ethmoids and sphenoids. The tumor had invaded the medial wall and floor of the left orbit. (Figure 1)

A variation of the Weber Ferguson incision consisting of a lip split, a subciliary incision with a 2-3 cm lateral extension and a vertical incision to cut the forehead flap was performed. (Figure 2)

Tumor was excised through the exposure. The left orbit was preserved, but the medial and inferior orbital wall was resected, together with both maxillae, the nasal bone, and septum.

Orbital Reconstruction was done using a coronoid-temporalis pedicled flap (tcs) anchored to the lateral orbital wall remnant, and an island forehead flap (ff) sutured to the temporalis muscle. (Figure 4)

Both flaps were supplied by distinct arteries and therefore had increased chances of survival. Because of their accessibility, the additional operative time was only 30 minutes.

Post operatively, there was no diplopia, blurring of vision or foreign body sensation of the eye. The mild epiphora was expected due to surgically absent lacrimal drainage.

The combination of forehead and temporalis flaps has previously only been used to fill defects from orbital exenteration, as described by Christo in $2002^{3}$. This technique demonstrates their versatility in orbital reconstruction, restoring function with the ease of application and minimal cost.

Local flaps can be combined in order to repair the orbital floor
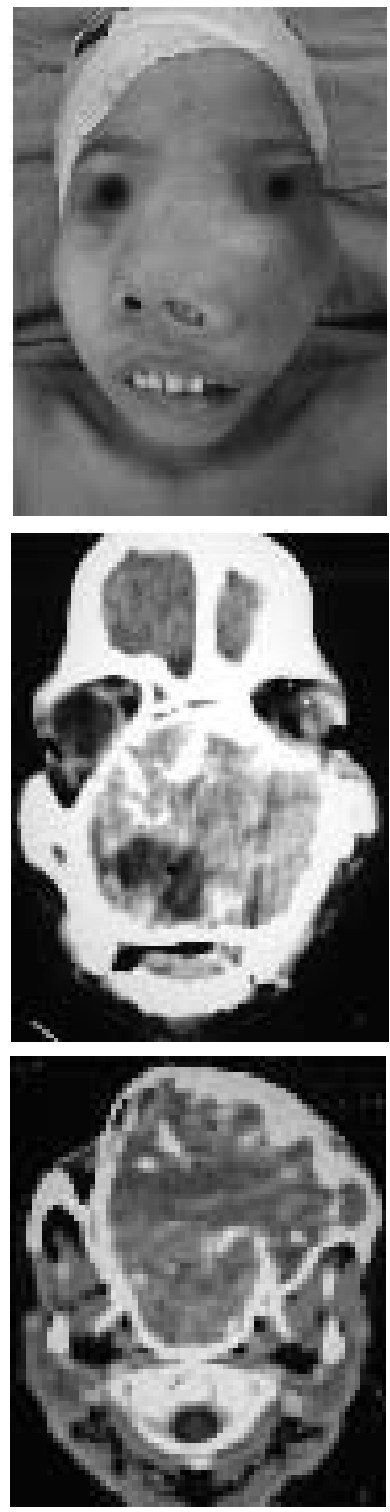

Fig. 1

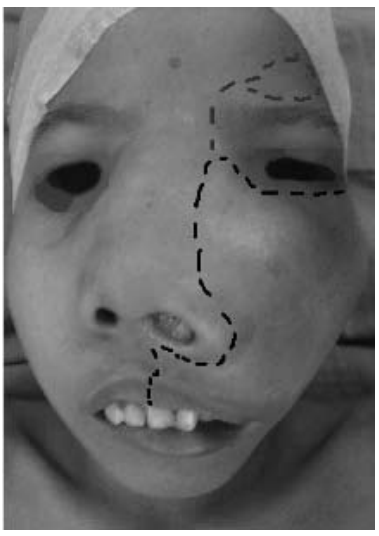

Fig. 2 


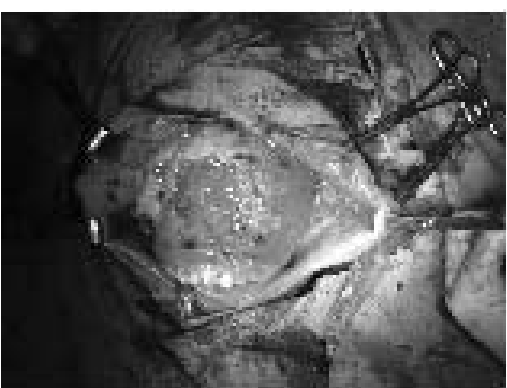

Weber Ferguson exposure

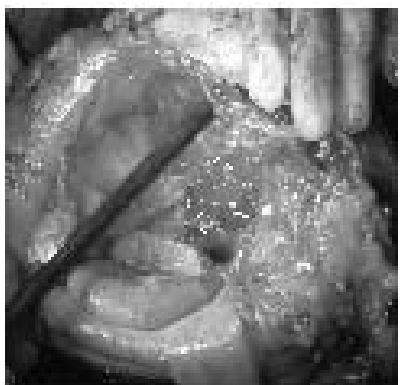

Post-excision defect

Fig. 3
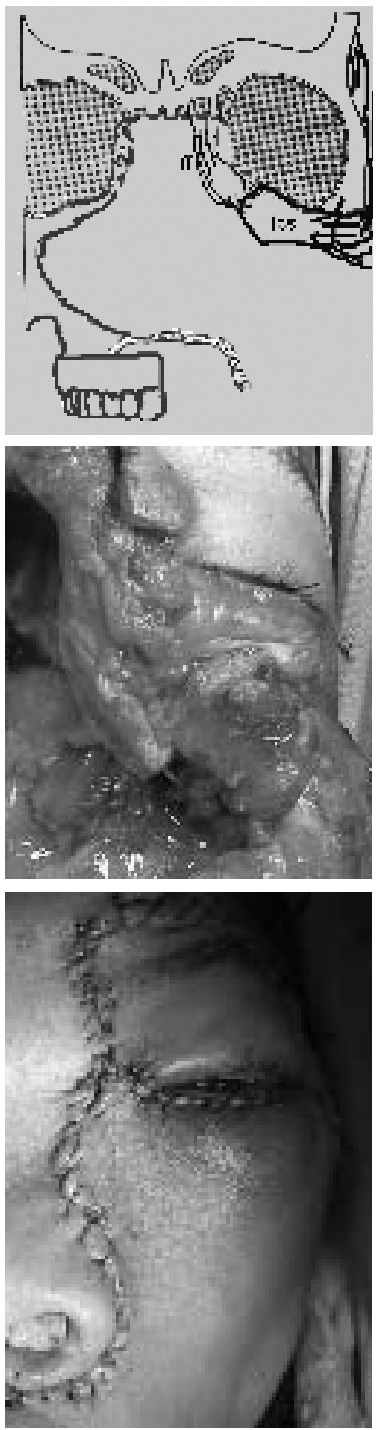

following radical maxillectomies. The versatility and ease of the temporalis-coronoid swing and the forehead island flap enable good orbital support after total maxillectomy with orbital preservation. Minimal functional and cosmetic deformity can be achieved in the reconstruction of the orbital floor without more extensive surgery, added cost or long operative time.

REFERENCES:

1. Curioni C, Toscano P, Fioretti C, Salerno G. Reconstruction of the orbital floor with the musclebone flap (temporal muscle with coronoid process). J Maxillofac Surg. 1983 Dec;11(6):263-8.

2. Pryor SG, Moore EJ, Kasperbauer JL, Hayden RE, Strome SE. Coronoid-temporalis pedicled rotation flap for orbital floor reconstruction of the total maxillectomy defect. Laryngoscope. 2004 Nov;114(11):2051-5.

3. Christo $\mathrm{S}$. Temporalis muscle flap and forehead flap for a single stage primary repair of the orbit after exenteration. West Afr J Med. 2002 Jul-Sep;21(3):248.

4. Birt BD, Antonyshyn $\mathrm{O}$, Gruss JS. The temporalis muscle flap for head and neck reconstruction. J Otolaryngol. 1987 Jun;16(3):179-84.

5. Clauser L, Curioni C, Spanio S. The use of the temporalis muscle flap in facial and craniofacial reconstructive surgery. A review of 182 cases. J Craniomaxillofac Surg. 1995 Aug;23(4):203-14.

6. Holmes $\mathrm{S}$, Hutchison I. Reconstruction of the orbital floor after its removal for malignancy. Br J Oral Maxillofac Surg. 2001 Apr;39(2):158-9.

7. Lari AR, Kanjoor JR, Vulvoda M, Katchy KC, Khan ZU. Orbital reconstruction following sino-nasal mucormycosis. Br J Plast Surg. 2002 Jan;55(1):72-5. 